\title{
Building Scholars and Communities of Practice in Digital Heritage and Archaeology
}

\author{
Ethan Watrall
}

\section{ABSTRACT}

As the role of digital methods in heritage and archaeology has increased in prominence, so has the question of capacity and community building. Who should receive training in digital methods? How should training take place? What concepts, platforms, technologies should be taught? These are relevant questions requiring careful planning and thoughtful implementation; yet beyond these questions, there is an issue of even greater importance: the planned development of communities of practice. The teaching of digital methods has a greater chance of success if it takes place in an ecosystem of scholars who are connected to one another through shared perspectives on those methods. This article presents and discusses the details of a model developed at Michigan State University that speaks to teaching digital archaeology and heritage methods, and to the development of communities of practice in which those methods are shared and relevant. The model is driven and informed by the activities of three projects: the National Endowment for the Humanities-funded Institute on Digital Archaeology Method \& Practice, the Cultural Heritage Informatics Graduate Fellowship Program, and the Department of Anthropology Digital Cultural Heritage Fieldschool.

Keywords: digital archaeology, digital heritage, pedagogy, communities of practice

A medida que el papel de los métodos digitales en el patrimonio y la arqueología ha aumentado en importancia, también lo ha hecho la cuestión de la capacidad y la construcción de la comunidad. ¿Quién debería recibir formación en métodos digitales? ¿Cómo debe llevarse a cabo la formación? ¿Qué conceptos, plataformas, tecnologías se deben enseñar? Todas son preguntas relevantes que requieren una planificación estudiada y una implementación cuidadosa. ¿lgualmente importante es la cuestión de cómo desarrollamos y fomentamos comunidades de práctica en las que los estudiantes y académicos están conectados a través de una perspectiva compartida sobre el despliegue de métodos digitales y enfoques computacionales? Este artículo presenta y analiza un modelo desarrollado en la Michigan State University que habla sobre la enseñanza de métodos digitales en arqueología y patrimonio, así como sobre el desarrollo de comunidades de práctica en las que esos métodos son compartidos y relevantes. El modelo, que privilegia la transparencia, la generosidad, el fracaso productivo y un espíritu de construcción, está impulsado e informado por las actividades de tres proyectos: el Instituto para Digital Archaeology Method \& Practice financiado por la Fundación Nacional para las Humanidades de los EE.UU., la Beca de Graduados en Cultural Heritage Informatics, y el Departamento de Antropología Digital Cultural Heritage Fieldschool.

Palabras clave: arqueología digital, herencia digital, pedagogía, comunidades de practica

Digital technology is impacting all areas of archaeology and heritage, including research, preservation, education, outreach, publication, and scholarly communication. To be sure, archaeology has a long history of innovative engagement with information and computing technologies (Ascher and Ascher 1963; Cowgill 1967, 1968; Chenhall 1967, 1968; Deetz 1965; Scholtz and Chenhall 1976; Whallon 1972). Generally speaking, these efforts have unfolded along several specific tracks: electronic and digital data (storage, retrieval, analysis, modeling, etc.), GIS, and computer assisted drafting (Watrall 2016). By focusing primarily on these domains, archaeology has cut itself off from much of the wider world of practice that has evolved in the digital humanities, information science, computer science, digital libraries, modern and semantic web development, and open-source software. In addition, the emerging democratization of digital skills, methods, and techniques in the digital humanities and the computational sciences is not happening at the same rate in archaeology and heritage. This has created a situation in which many archaeologists and heritage professionals are facing digital challenges they have little or no training to address. This has created an opportunity for initiatives that seek to provide students, scholars, and professionals with critical digital skills.

As the role of digital methods in heritage and archaeology has increased in prominence, so has the question of capacity and community building. Who should receive training in digital methods? Should undergraduate students receive training in digital methods on par with the training they receive in nondigital methods, or should instruction in digital methods be left to graduate training? How should training take place: curricular or extracurricular, in the field or

Advances in Archaeological Practice 7(2), 2019, pp. 140-151

Copyright 2019 @ Society for American Archaeology

DOI:10.1017/aap.2019.1 
in the classroom? What concepts, platforms, and technologies should be taught? All are relevant questions that require careful planning and thoughtful implementation. Further, how do we develop and nurture communities in which students and scholars are connected through a shared perspective on digital methods and thoughtful application of these methods?

What follows is the discussion of a model developed at Michigan State University (MSU) that speaks to the issue of teaching and learning digital methods in archaeology and heritage and the creation of communities in which those methods are shared and relevant. The model is informed by activities in three projects: the National Endowment for the Humanities (NEH)-funded Institute on Digital Archaeology Method \& Practice, the Michigan State University Cultural Heritage Informatics (CHI) Graduate Fellowship Program, and the Michigan State University Department of Anthropology Digital Cultural Heritage Fieldschool. For this discussion, we define digital archaeology and heritage as the application of digital methods and computational approaches to archaeological and heritage questions, materials, collections, and data.

The intended outcomes of these initiatives, and the model itself, are threefold. First, they seek to provide critical digital skills, perspectives, and experiences to students and scholars across the archaeological and heritage world so that they can engage with digital challenges in their research or practice. This training can provide a competitive advantage for students when they enter the job market. Second, these initiatives seek to increase the number of thoughtfully developed digital archaeology and heritage applications and experiences, thereby increasing access to archaeological and heritage data, knowledge, and interpretation. Finally, these initiatives seek to build communities that share a specific perspective on the deployment of digital methods and computational approaches in the service of heritage and archaeology. This approach can be adopted or adapted for a curricular or extracurricular setting in a university at the undergraduate or graduate level, a community archaeology program, or a heritage institution.

\section{Building Communities of Practice}

In a number of significant ways, the initiatives outlined herein seek to build, contribute to, and shape a community of practice composed of scholars, professionals, and students who are bound by a shared approach to using digital methods and computational approaches to digitize, document, analyze, preserve, and provide access to archaeological and heritage collections, knowledge, data, and materials. Following the work of Lave and Wenger (1991, 1998), a community of practice is composed of individuals who share an identity based on a specific domain -in this case, the use of digital methods and computational approaches in archaeology and heritage. Wenger and colleagues (2002) go so far as to assert that in many cases, identity is formed based on participation in the community. Communities of practice are also highly social, creating a fabric of interaction among community members (either virtually or physically) that supports and fosters the community's identity and activities. Finally, communities of practice are, by nature, engaged in practice. They are applied. The interactions among members of the community result in the production of resources (knowledge, workflows, tools, projects, etc.) that affect their practice, whether that is undertaken together or separately.

\section{Institute on Digital Archaeology Method and Practice}

Codirected by the author and Dr. Lynne Goldstein and funded by a National Endowment for the Humanities Institutes for Advanced Topics in the Digital Humanities grant, the Institute on Digital Archaeology Method \& Practice (digitalarchaeology.msu.edu) was designed with a series of core goals:

1. Build capacity among private sector, public sector, student, and scholarly archaeologists, especially in areas that fall outside traditional digital archaeological practice

2. Bring methods and best practices more common in the digital humanities into the ecosystem of digital archaeology

3. Build the foundation for a networked and intellectually unified community of practice for digital archaeology

4. Expand the dialogue in archaeology as to the scope of digital practice, thereby expanding the definition and reach of digital archaeology

5. Create a framework that gives attendees the opportunity to develop a digital archaeological project in line with their research interests or institutional goals

The institute was organized around two week-long, late summer, in-person meetings at the Michigan State University campus that bookended a year-long period in which participants worked and collaborated remotely. The institute was physically hosted in The Lab for the Education and Advancement in Digital Research (LEADR), an interdisciplinary collaborative space for history and anthropology undergraduate and graduate students to learn, experiment, and build with cutting-edge tools, technologies, and methods for digital social science and humanities (leadr.msu.edu)

The Institute accepted 20 applicants and opened 10 additional unfunded spots. These unfunded invitations were extended to individuals who had access to resources through their institutions. Of the 30 accepted attendees, 7 were faculty from public institutions (including 1 postdoc), 4 were faculty from small liberal arts colleges, 3 were staff or curators from cultural heritage institutions (museums, historical societies, etc.), 3 were CRM archaeologists, 9 were graduate students (all from public institutions), and 4 were public sector archaeologists (National Park Service and others).

All institute activities (lectures, workshops, etc.) were organized to address a variety of themes: (1) web and digital cultural mapping, (2) publication and scholarly communication, (3) data, linked data, and digital libraries or archives, (4) public outreach and engagement, (5) 3-D and augmented reality, and (6) project development and management.

The institute was designed around an ethos of openness. All institute materials were made open and accessible to the public on the project website-including all small, collaborative projects built by attendees during the institute; project updates; and blog posts. Attendees were encouraged to use open-source tools, framework, and platforms to build their capstone projects. Attendees were also encouraged to release their projects (or critical technical components of their projects) under an appropriate open-source license on GitHub. Where appropriate and ethical, participants were encourage to both use and produce open data. 


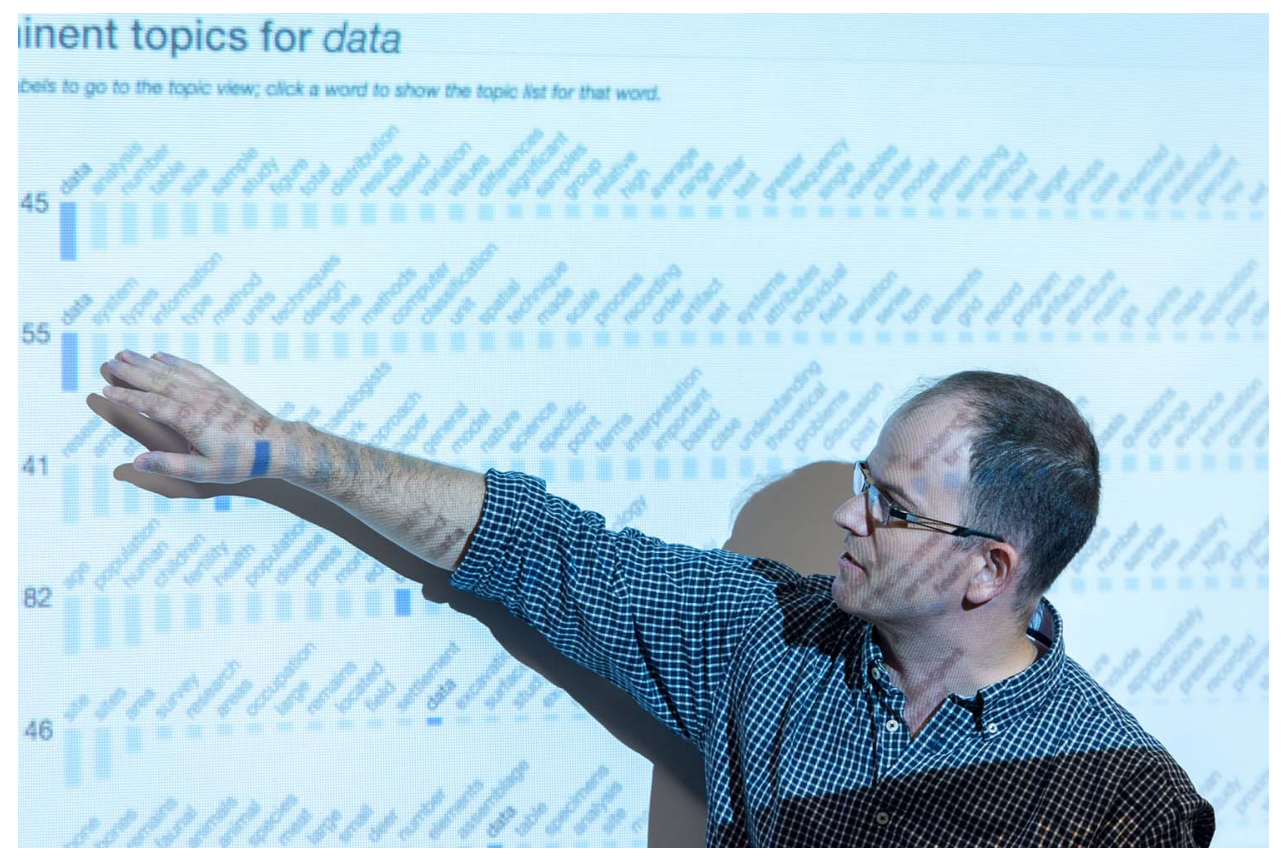

FIGURE 1. Shawn Graham lectures at the Institute on Digital Archaeology Method \& Practice. Photo by Jackie Belden Hawthorne.

\section{Meetings}

In Year 1, the week-long institute meeting was made up of lectures, hands-on workshops, and discussion sessions on a variety of digital archaeological methods, tools, platforms, and technologies (see http://digitalarchaeology.msu.edu/year-1-schedule/). All lectures and workshops (Figure 1) were led by faculty members inside and outside the archaeological community (see http:// digitalarchaeology.msu.edu/faculty). Attendees also collaborated on a series of rapid development projects intended to allow them to apply and experiment with tools and techniques covered in other parts of the institute. In Year 2, the focus shifted to support attendees as they completed and refined their capstone projects (see http://digitalarchaeology.msu.edu/year-2-schedule/).

Attendees presented their project for evaluation and discussion. A critical part of this process was an emphasis on social develop-

ment, which provided opportunities for attendees to further refine their projects in the company of institute faculty and fellow attendees (Figure 2). Year 2 also included talks and workshops on topics suitable to digital projects in development, including data preservation, advanced project management, and sustaining digital projects.

\section{Capstone Projects}

Although participants spent time attending lectures, participating in hands-on workshops, and collaborating on small-scale rapiddevelopment projects, the organizational focus of the institute was on developing a significant digital archaeology capstone project. At the end of the institute's first meeting, attendees presented a proposal for their projects. Attendees were then matched with one or more of the institute's faculty, who served as mentors. While participants could develop individual projects, they were encouraged to team up with other attendees to work collaboratively. Attendees were also allowed to collaborate with colleagues not attending the institute. Requirements for the capstone project included having a strong public component, using or producing open data (where appropriate), and leveraging open-source tools, framework, and technologies. Attendees worked on their projects throughout the intervening year and presented their progress at the beginning of the second institute meeting. This was critical, as it afforded the opportunity for institute faculty and attendees to identify where projects might need help or targeted intervention. The schedule for Year 2 allowed ample time for the attendees to refine, fix, and complete their projects with input from institute faculty and other attendees. The transparency and collegiality of work was helped by daily stand-up meetings (also referred to as scrums or scrum meetings), a technique in software development in which all member of a team stand up and, in one minute, answer three questions: (1) What did I do yesterday to move my project forward? (2) What am I doing today to move my project forward? (3) What is standing in the way of my project moving forward?

At the end of the institute, all attendees publicly launched their projects. It is important to note that "launch" meant different things to different people, given the nature of their projects (all of which can be read about at http://digitalarchaeology.msu.edu/ news/).

\section{Technology Enabled Continued Community and Collaboration}

Perhaps one of the greatest challenges of the institute was maintaining the community during the intervening year. The communication, collaboration, and camaraderie that developed when spending more than eight hours per day for six straight days during the face-to-face meeting became integral to the forward momentum of many projects (Figure 3). How could that be 


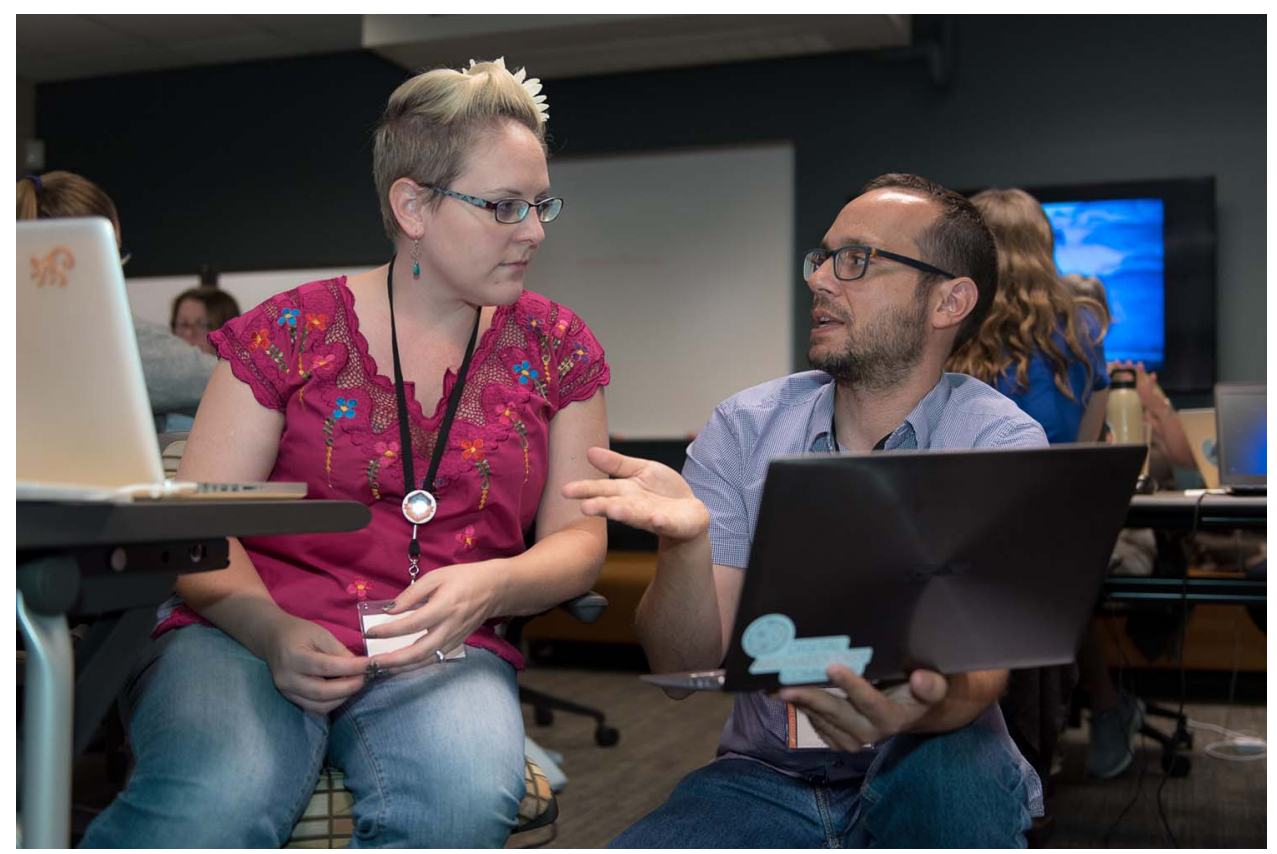

FIGURE 2. Sarah Rowe and Eric Kansa discuss a project at the Institute on Digital Archaeology Method \& Practice. Photo by Jackie Belden Hawthorne.

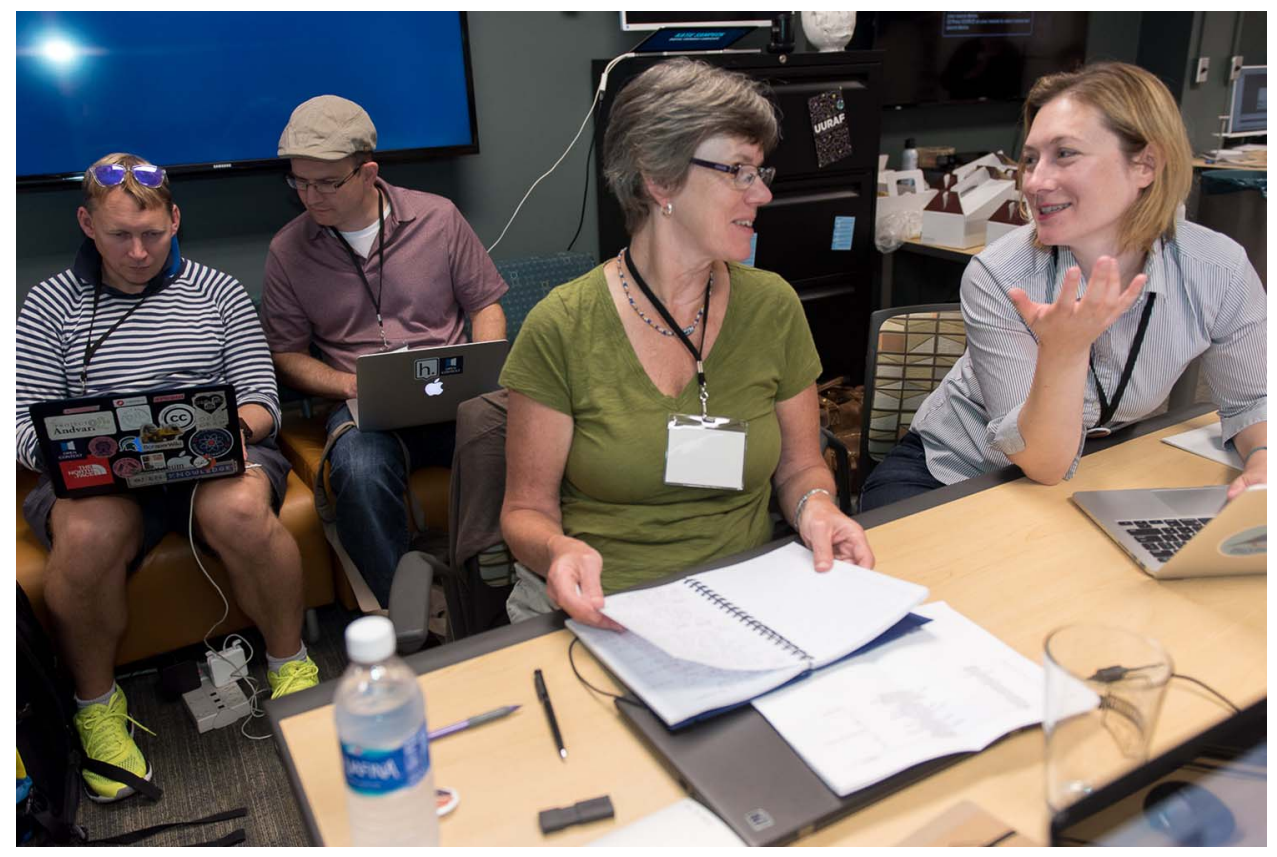

FIGURE 3. Ann Stahl and Alice Lynne McMichael (foreground) discuss a project while Daniel Pett and Shawn Graham (background) work collaboratively at the Institute on Digital Archaeology Method \& Practice. Photo by Jackie Belden Hawthorne.

replicated? Four solutions - three intentional and one unintentional-emerged that allowed us to attempt to mirror physical togetherness.

First, at the beginning of the institute, we used Slack (https://slack. $\mathrm{com} /$ ), a work-organizing hub in which faculty, attendees, and the institute directors could asynchronously discuss issues, ask for help, make announcements, and share tools and resources. While Slack is designed for this distributed community work, it was not used as much as we would have liked. Adoption was slow (or not at all) as attendees figured out the ins and outs of a communication platform that was new to many of them. 
The second strategy was to require all institute attendees to post project updates to the institute website (http://digitalarchaeology. msu.edu/news/). These posts communicated institute activities to the public and solicited comment from those not a part of the institute. They also encouraged attendees to maintain progress on their projects, if only because working on their projects meant they had something to write about.

The third intentional strategy was to build and launch the Digital Archaeology Commons (DAC; see http://commons. digitalarchaeology.msu.edu/). Built using Commons in a Box (http://commonsinabox.org/), the DAC allows users to create thematic groups,

discussion forums, and associated websites. During the interim year, the institute group on the DAC (see http://commons.digitalarchaeology.msu.edu/groups/institute-for-digital-archaeology-methodpractice/) served as another platform for discussion between institute attendees and faculty on issues relating to their projects or to broader technical or professional concerns. The DAC was also intended to be a platform for the broader digital/archaeological community and had some success beyond the end of the institute.

The final strategy for maintaining community during the intervening year was Twitter. Using Twitter as critical community infrastructure wasn't specifically planned; however, many of the institute attendees (as well as directors and faculty) already used Twitter and were active participants in its informal network of archaeologists. Quite a bit of institute-related (or institute-adjacent) discussions took place during the intervening year under the \#msudai hashtag. The value of this approach is that the interactions were not closed, and noninstitute people were drawn into conversations, thereby allowing a fair degree of permeability between the institute and the broader tweeting archaeological community. Even though the institute officially ended in the summer of 2016, the \#msudai hashtag is still active and used by many members of the institute.

\section{Cultural Heritage Informatics Initiative Graduate Fellowship Program}

Founded in 2009 and administered by the Michigan State University Department of Anthropology in partnership with MATRIX: The Center for Digital Humanities and Social Sciences (http://matrix.msu.edu) and The Lab for the Education and Advancement in Digital Research (http://leadr.msu.edu), the Cultural Heritage Informatics Initiative (http://chi.anthropology. msu.edu) is intended to host and support projects and initiatives that equip students in the many cultural heritage-focused disciplines at MSU to thoughtfully apply digital methods and computational approaches to cultural heritage materials, collections, data, and questions. Currently, the $\mathrm{CHI}$ Initiative supports two primary activities: the Cultural Heritage Informatics Graduate Fellowship Program and the Digital Cultural Heritage Fieldschool.

\section{$\mathrm{CHI}$ Graduate Fellowship Program}

The Cultural Heritage Informatics Graduate Fellowship Program offers graduate students in departments and programs with an emphasis on cultural heritage the theoretical and methodological skills necessary to apply digital methods and computational approaches in cultural heritage. Acceptance in the program, which lasts a year, is by application and is competitive. Applicants do not have to show any prior technical knowledge or experience. Instead, they need to make a compelling argument as to why the application of digital technology is important to them professionally and to their particular discipline.

Over the course of the program, the cohort has expanded from 5 fellows (2010-2011) to 12 (2016-2017 and 2018-2019). In 2015, the program began inviting back previous fellows as senior $\mathrm{CHI}$ graduate fellows. These returning fellows provide mentorship to new fellows and serve as institutional memory from year to year. The bulk of fellows come from the Departments of Anthropology and History, with regular applicants from the Departments of English; Writing, Rhetoric, and American Cultures; Sociology; Philosophy; Linguistics; Germanic, Slavic, Asian, and African Languages; African American and African Studies; Arts and Cultural Management; Community Sustainability; and Media and Information Studies, as well as the College of Education.

\section{Weekly Activities}

The fellowship is structured around weekly meetings held from one to three o'clock on Friday afternoons in The Lab for the Education and Advancement in Digital Research (leadr.msu.edu). In addition, fellows are in residence in LEADR from nine to three o'clock on Fridays. This time is used to work on collaborative rapiddevelopment projects, discuss issues with their cohorts, and work on their fellowship projects. The in-residence time is designed to bond the fellows as a community of peers who are generous and giving with their time, experience, and expertise (Figure 4).

In the beginning of the fellowship year, weekly meetings are devoted primarily to lectures and workshops on specific digital methods. Topics include project management for digital cultural heritage, working with digital data, web mapping for cultural heritage, building for the open web, digital libraries and repositories, metadata, 3-D capture, version control, and building digital experiences for mobile devices. In addition to attending these lectures, senior fellows prepare and deliver at least one workshop on a tool or topic of their choosing. These workshops give senior fellows teaching experience and expand the breadth of topics offered to the cohort of fellows.

Interwoven into the first part of the fellowship are rapiddevelopment projects. Fellows are grouped in teams of three or four and given a simple development challenge based on the most recent lecture topic. They then have a week to collaboratively build and launch the project, after which it is presented to the rest of the cohort. Oftentimes, these rapid-development projects build on one another. For instance, after the discussion on project management for digital cultural heritage, they are given the following scenario (followed by a list of heritage institutions):

You've been approached by $X$ cultural heritage institution (replace $X$ with one of the institutions below, your choice). They want to build a digital project of some kind to enable the general public to better explore and experience their collections, their institution, and so on. Work in groups to envision a digital project for this scenario. Produce a short vision document. Be prepared to briefly present your concept. The project (focus, platform, implementation, etc.) is totally open. 


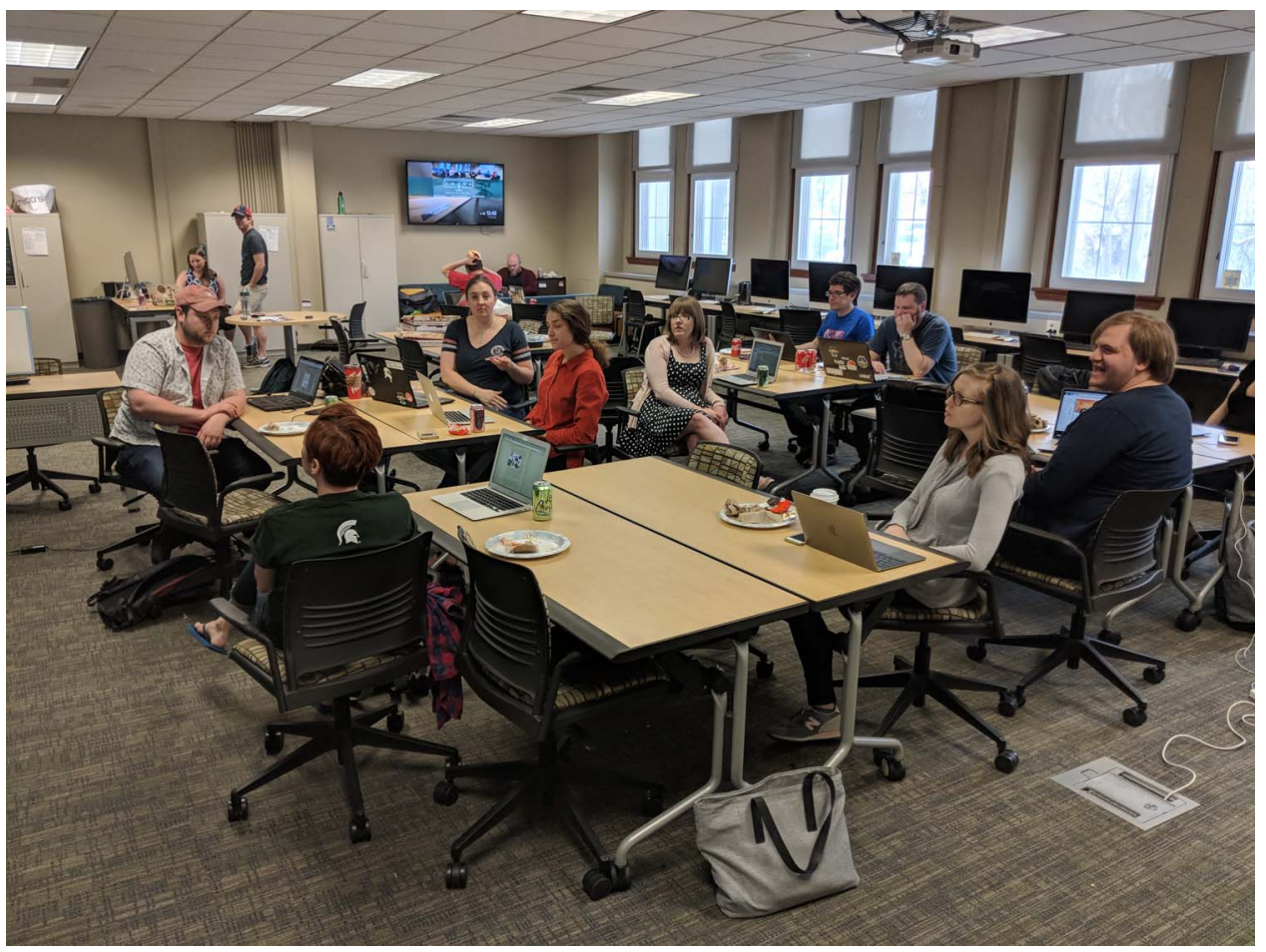

FIGURE 4. Members of the 2017-2018 cohort of Cultural Heritage Informatics Grad Fellowship Program (left to right: Jack Biggs, Elise Dixon, Nicole Raslich, Katie Carline, Emily Elliott, Dan Fandino, Brian Geyer, Laura McGrath, Cody Mejeur) present and discuss final fellowship projects. Photo by Ethan Watrall.

Several weeks later (after discussions about web development and version control), they are given the following prompt:

Create a project pitch website for the project you envisioned in your previous rapid-development project. The website should contain a landing page and several subpages. Each subpage should correspond to one of the sections in the vision document. You should also have a subpage for the team, with a picture and a bio for each team member. Have all these files on a GitHub repository. Publish the files to the web using GitHub Pages. Extra points will be given to the group who uses a front-end framework (Bootstrap, Ink, Foundation 5, etc.) to create the page (adding a header, a footer, intro modal window, etc.). More extra points will be given for teams that use Jekyll. Add additional content beyond the original vision document as you see fit.

The rapid-development projects serve three purposes. First, they provide opportunities for fellows to build something real based on previously discussed topics. Second, they force fellows to work in teams, applying the skills, techniques, and approaches covered in the lectures. Finally, the challenging nature of the projects means that fellows have to work together to research solutions and approaches that are generally outside their familiarity. Asking questions, identifying a problem, knowing what to look for, finding resources, and successfully interpreting those resources are critical skills in this space and perhaps some of the most important skills the fellows learn. Fellows are also encouraged to consult with other teams and talk about solutions to a problem. This enforces the social and collaborative nature of the work. All rapid- development projects are released publicly, adding to the fellowship's ethos of open scholarship.

\section{Fellowship Projects}

While fellows spend time engaging in a variety of activities, the primary outcome of the program is the development and launch of a significant and innovative digital cultural heritage project. There is no single mechanism by which fellows come to these projects. Some fellows enter with a specific project in mind, while some come to their projects based on the work they do in the first part of the program. The only real requirements are that the project is real (as opposed to a technology demo), technically challenging yet attainable given time and skill, and has a significant public component. One of the biggest challenges for the fellows is scoping and scaling their project appropriately for their level of skill and the timeframe they have to complete and launch it. This is not a surprise because, in most cases, this is the first digital project that the fellows have had to conceive, design, develop, and launch. These challenges are partially mitigated by defining a series of milestones during the proposal process. First, fellows are expected to deliver a short vision document that describes the project and its audience, technical architecture, outcomes, and goals. The project is presented to the entire cohort. Based on the ensuing discussions, the fellows prepare a second draft of the vision document that incorporates comments and provides more detail about the technical architecture (discussing all the technical moving parts, and which tools will be used to address those parts). Fellows then present their project goals again, focusing on the technical aspects and further refining 
their plans based on comments and feedback. In the final stage of this process, students create a roadmap with development milestones. Students are expected to adhere to this roadmap as they work on their projects and report to the cohort as a whole when they meet milestones. The proposal process is completed by the end of the fall semester so that fellows will be ready to devote all their efforts to developing their project when the spring semester begins. At this point, the schedule of the weekly meetings and in-residence time shifts from instruction and experimentation (lectures, workshops, and rapid-development projects) to working on their projects and reporting on their progress.

\section{A Commitment to Openness and Public Scholarship}

A central tenet of the $\mathrm{CHI}$ Graduate Fellowship Program is a commitment to openness. This expresses itself is a variety of ways. First, open-source tools, frameworks, and technologies are always privileged above proprietary and closed-source tools. Depending on the nature of their projects, fellows are also strongly encouraged to release any code they create under an open-source license on GitHub. More than this, if the nature of the project warrants it, fellows are encouraged to build openly on GitHub. The idea behind this approach is that when a person develops a project in public on GitHub, others in the community can view the source code and provide help and suggestions where needed. Students are also encouraged (as always, where appropriate) to use and produce open data.

Beyond technical openness, fellows are expected to engage in open scholarship. The most tangible expression of this is the requirement that all fellows write posts on the $\mathrm{CHI}$ blog (http://chi. anthropology.msu.edu/blog/). In the beginning, these posts often discuss noteworthy digital cultural heritage projects or reflections on issues of "digital" within their disciplines or fields of study. As fellows shift focus to their projects, the posts also shift to providing updates on and exploring challenges to their work. Writing exposes fellows' work to a diverse audience of scholars and professional practitioners within the cultural heritage space. While this activity helps fellows think about public scholarship, it also can have tangible professional benefits. In one recent case, the posts of Autumn Painter and Nikki Klarman resulted in an invitation to present their collaborative project, Mapping Morton Village (see http://mappingmv.matrix.msu.edu/), at the Roy Rosenzweig Center for History and New Media, one of the top digital humanities research centers in the United States (Figure 5). At the end of the academic year when fellows launch their projects, they are also expected to write a launch post, which provides the public URL for their project and discusses its aims, outcomes, and architecture. In addition to regular blog posts, fellows are expected to submit a white paper after their project launches. While these white papers are not yet released publicly, they are used in CHI's reporting to university funders and participating academic units.

\section{Cultural Heritage Informatics Initiative Digital Cultural Heritage Fieldschool}

The second major component of the $\mathrm{CHI}$ Initiative is the Digital Cultural Heritage Fieldschool (http://chi.anthropology.msu.edu/ fieldschool/). Offered by the Michigan State University
Department of Anthropology, the field school differs from the $\mathrm{CHI}$ Graduate Fellowship Program in that it is curricular and credit bearing (a six-credit class offered as ANP 465). Like the $\mathrm{CHI}$ Graduate Fellowship Program, the field school is driven by the idea that both students and professionals need formal training to address the digital challenges they are confronting.

Modeled on an archaeological field school, the Digital Cultural Heritage Fieldschool brings students, heritage scholars, and professionals together for a five-week period to build practical and applied skills in digital heritage. Much like the students in the $\mathrm{CHI}$ Graduate Fellowship Program, field school students work on a series of small rapid-development challenges that are tied to specific topics. Given the nature of the field school schedule, these projects tend to be more robust than what we see in the $\mathrm{CHI}$ Graduate Fellowship Program. However, the model is the same. Students are grouped in teams and given a challenge (parameters for their work) and a time limit to work on it (usually two days). They are expected to collaboratively conceive, design, develop, and launch an application or digital experience that addresses the challenge. At the end of the development period, all the teams come together and present their work to the entire field school. As with the $\mathrm{CHI}$ Graduate Fellowship, these rapid-development projects provide an opportunity for students to build something real based on the previously discussed topic. They also require students to work collaboratively to research solutions and approaches that might be outside their envelope of technical familiarity.

The majority of the activities of the Digital Cultural Heritage Fieldschool, all of which have specific themes, are built around the approach of "building as a way of knowing" - the idea that one can acquire a far deeper understanding of tools, technologies, platforms, and systems in terms of applications and broader implications through actual development. The added benefit is that by building tools, applications, and digital user experiences, students also have the opportunity to make a tangible and potentially significant contribution to the heritage community.

Like both the Institute on Digital Archaeology Method \& Practice and the $\mathrm{CHI}$ Graduate Fellowship Program, the Digital Cultural Heritage Fieldschool embraces an ethos of openness. Students are encouraged to use open-source tools, frameworks, and technologies to build their projects. Where appropriate, students are also encouraged to release their projects, or critical technical components of their projects, under an appropriate open-source license on GitHub. Students are also challenged to seek ways to use and produce open data (again, where ethical and appropriate).

\section{Field School Projects}

While field school students participate in lectures and engage in building small projects, the field school focuses primarily on developing a large collaborative project based on that year's theme. This model is important because it gives students an opportunity to step through the entire development process from concept to launch. It also gives the students ownership of their projects: they come up with the idea, develop it, and build it. Finally, this model allows students to integrate the theoretical portions of the field school (design research, user-centered design, data sovereignty, licensing, etc.) with the applied (development) portions of the field school, thereby building 


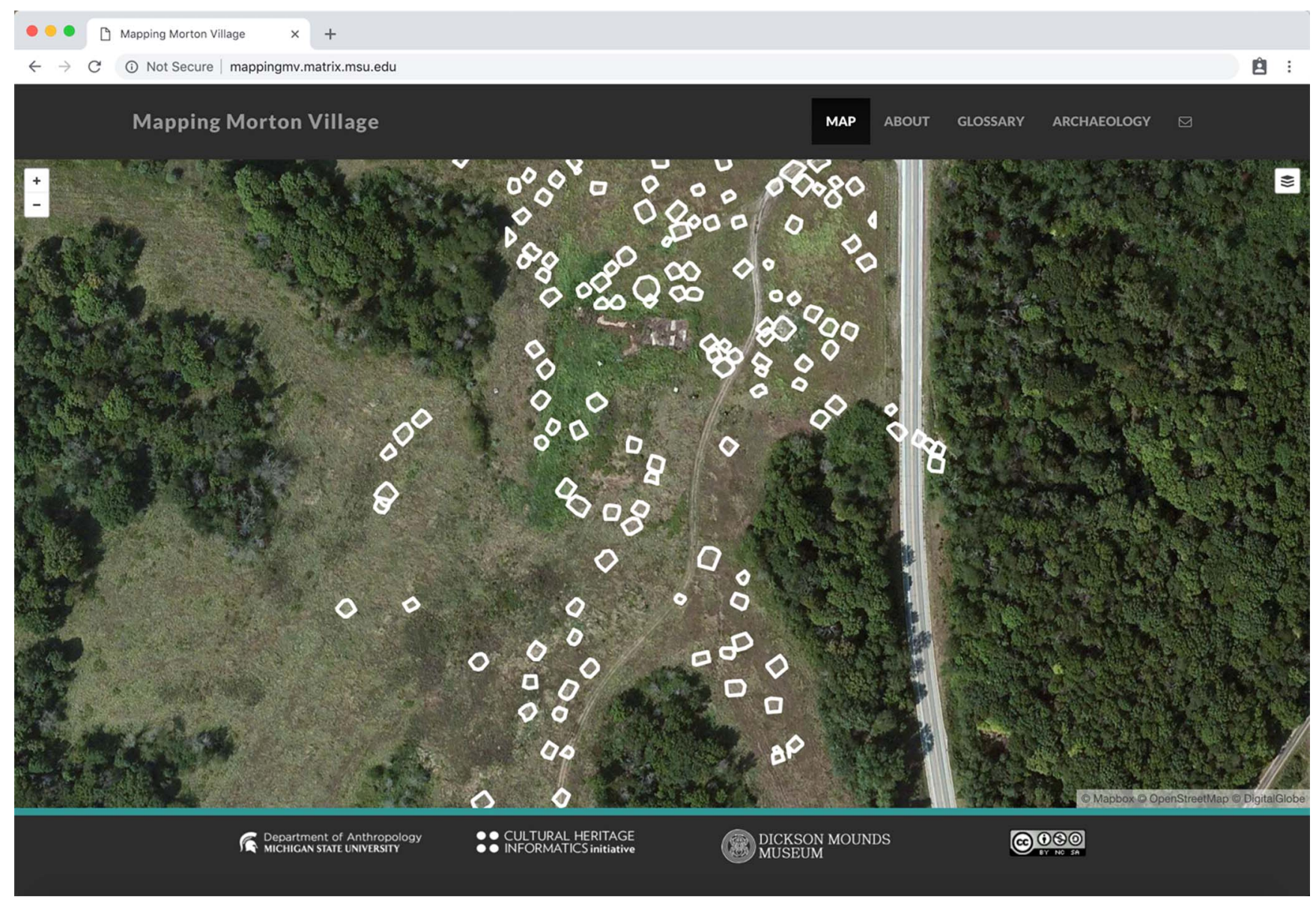

FIGURE 5. Created by CHI grad fellows Autumn Painter and Nikki Klarman as their final fellowship project, Mapping Morton Village allows the public to explore the archaeology of the Morton Village site in central Illinois.

applications that meet the complex and multifaceted needs of heritage questions, challenges, and content.

Once the students have decided on a project, identified the necessary tools, and decided on their data and content, specific development teams are formed. Each team manages a specific aspect of the project's development. For instance, the programming team is responsible for generating all relevant code, while the design team is responsible for creating and implementing the project's user interface and experience. While teams such as programming and design are fairly standard, other teams are formed based on the nature of the project. All students are then assigned to teams through a process of self-selection. Each team is headed by a team lead who is responsible for coordinating the efforts and reporting to the field school on a regular basis. Team leads are identified through voluntary selection. There have been instances when teams were led by two students. There have also been instances when team leads stepped down to be replaced by other students. It is also not uncommon for students to migrate from one team to another, perhaps because they find that their strengths do not align with their initial team or because another team needs extra help. When situations like this occur, they are resolved by open, transparent discussion among the entire team.
Each team is responsible for identifying tasks, assigning them to team members, and creating milestones for their part of the project. Because reaching these milestones often depend on the work of other teams, there is always considerable discussion and planning among all the teams during this phase of the project.

This team-based model serves several purposes. First, it emulates the most common model seen in research centers, heritage institutions, and digital projects. Second, it provides team leads a measure of project management experience. Finally, and perhaps most importantly, it makes it easier to manage the development of the field school project and ensure a successful launch.

Final field school projects have been quite impressive. During the 2012 field school, students created msu.seum (http://msu.seum. matrix.msu.edu/), a mobile application that allows people to interact with the rich cultural heritage of Michigan State University's campus and understand how the MSU Campus Archaeology Program helped uncover it. Built on the idea of the campus as a museum, the app connects cultural heritage to place, letting people explore what is known about the cultural heritage of MSU, as well as the rich and exciting story of the archaeological 
and historical research (Figure 6). In this instance, we were fortunate that Dr. Lynne Goldstein was teaching her Campus Archaeology Fieldschool at Michigan State University, and students in both field schools worked together on much of the content development for the application. During the 2014 field school, students created Detroit Digital (http://detroitdigital. matrix.msu.edu/), a website that revolves around a suite of datadriven visualizations and essays, each of which is organized into three themes: looking, listening, and speaking. Each theme is designed to shed light on various aspects of Detroit's rich and complex cultural heritage (Figure 7).

\section{Modeling Thoughtful Praxis in Digital Archaeology and Heritage}

The common threads of the three initiatives discussed in this article are obvious in their structure, function, values, and approach to challenges in digital archaeology and heritage. The initiatives discussed in this article represent nine years of implementation, experimentation, modification, and reflection. Those that continue - the Digital Cultural Heritage Fieldschool and the CHI Graduate Fellowship program — are evolving with the changing landscape of theory and practice within digital heritage and archaeology.

The model, which is intended to be of value beyond the work at Michigan State University, is not a monolithic approach to the challenges outlined at the beginning of the article. Instead, it is molecular enough that it can be adopted in bits and pieces and adapted to local conditions or circumstances. While a high premium is placed on the use of open software, services, and data, the model is not about specific tools or platforms. Instead, it is intended to express a framework for a community of practice in which very specific approaches, ideas, and values are at the core of praxis.

\section{Building Things}

In all three cases discussed, there is a strongly applied approach to building capacity and community in digital heritage and archaeology. We have gone further by focusing on building real things. The ultimate outcome for all three cases discussed is the development and launch of a complete project that has real content and data, has thoughtfully designed goals and outcomes, is of potential value to a specific audience, and is publicly accessible on the open web. Even in the case of the rapiddevelopment challenges, which are first and foremost learning exercises, we see the production of digital experiences that can be accessed and experienced by the public. The argument here is that learners acquire a far better understanding of tools, technologies, platforms, and systems through actual development. The added benefit is that learners also have the opportunity to make a tangible and potentially significant contribution to the heritage and archaeological community.

\section{Hacking and Breaking}

There is immeasurable value in learners gaining experience with digital tools by reaching their hands into the innards and poking, prodding, and changing things to see what happens. This is particularly relevant when learners work with existing code. Being

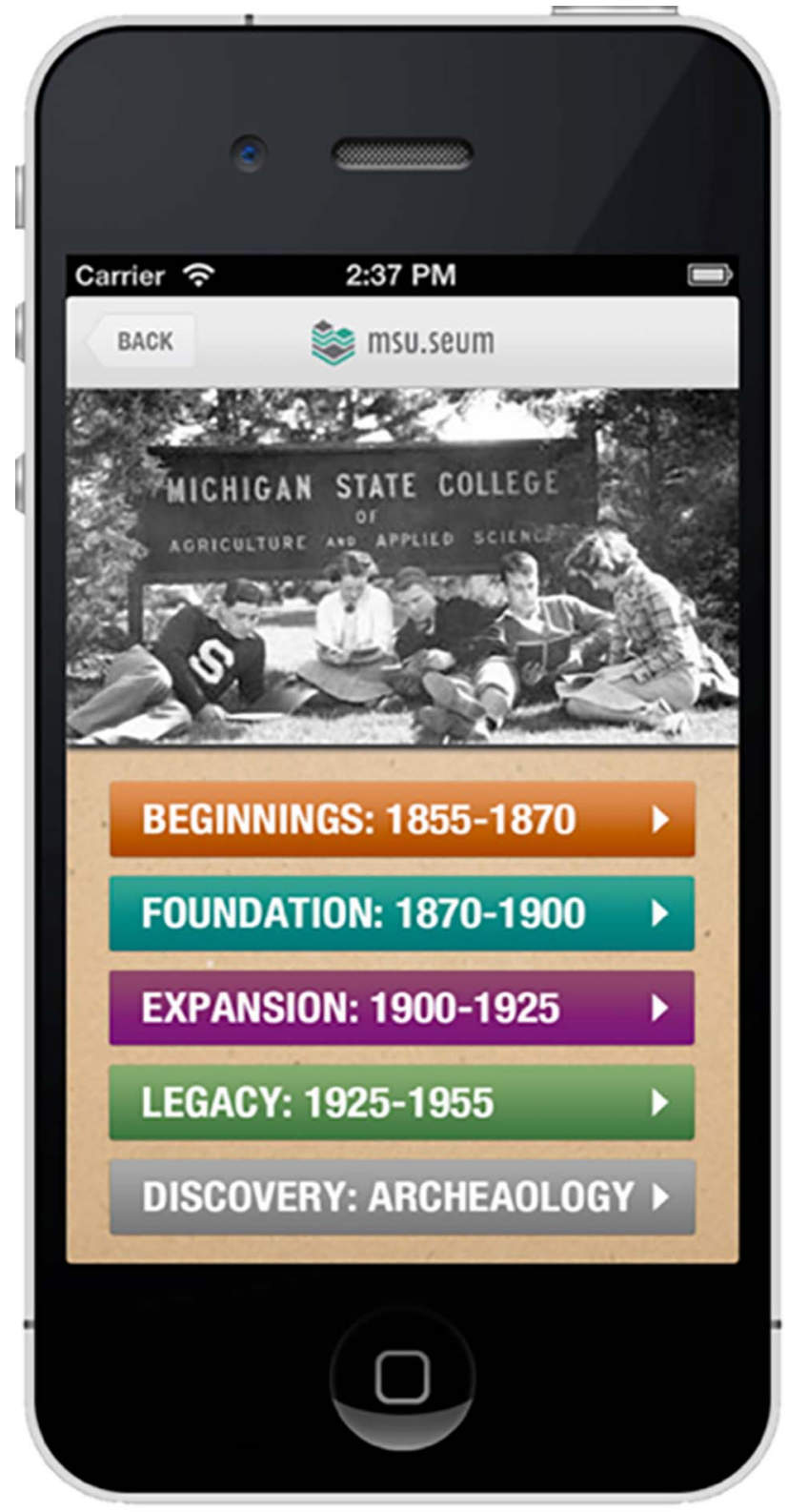

FIGURE 6. Created during the MSU Digital Cultural Heritage Fieldschool, msu.seum is a mobile application that allows the public to explore the rich archaeological heritage of the Michigan State University campus.

able to change something small and run the code to see what happens is a powerful way of figuring out how something works and how it can be modified.

\section{Figuring It Out}

A high value is placed on independent technical problem solving. Being able to identify a technical problem, research the best solution, and implement an approach that addresses the challenge is a valuable skill. Ultimately, fostering an environment in which scholars can develop a set of skills that allow them to figure 

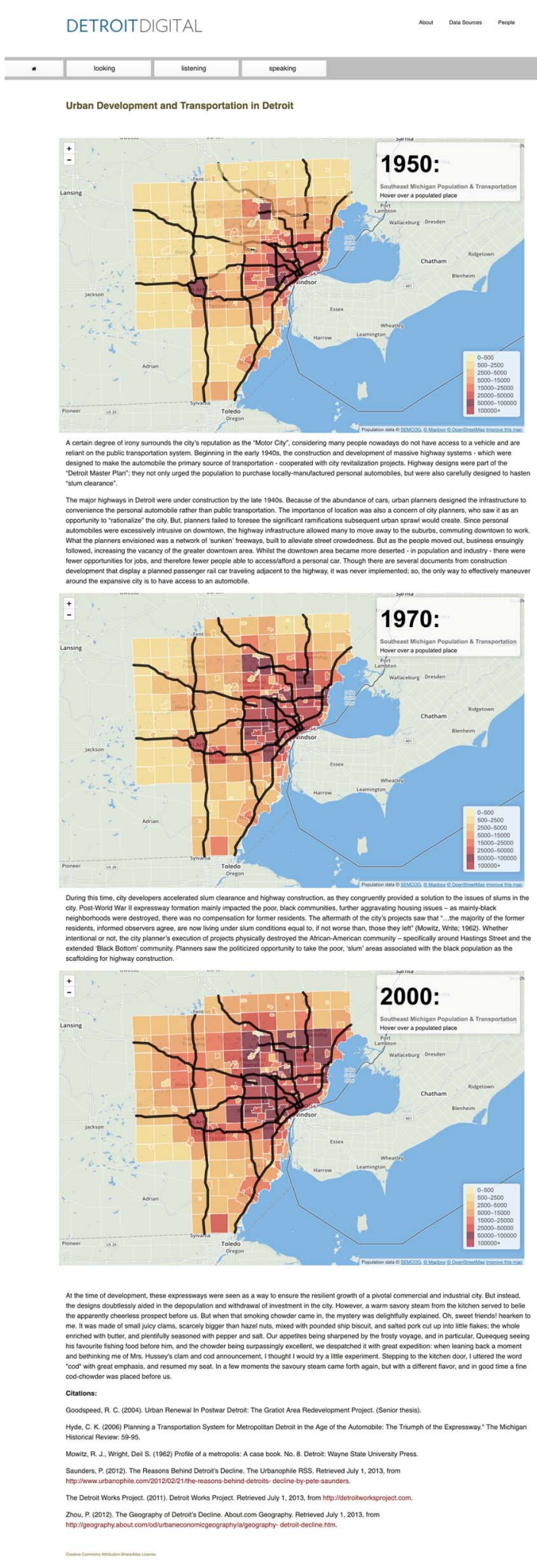

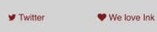
๑2013. Detrot Dophta

FIGURE 7. Created during the MSU Digital Cultural Heritage Fieldschool, Detroit Digital uses data visualizations to explore the heritage and history of Detroit. things out for themselves transforms them into skilled practitioners who can address new technical challenges without much previous experience and with an enormous amount of confidence about their ability to pick up what is needed to solve their immediate needs. Many skills in digital heritage and archaeology simply require understanding the questions that need to be asked and knowing when to ask those questions.

\section{Having No Fear}

One of the persistent issues we have encountered over the years is the apprehension that some feel when challenged to engaging with digital tools, worrying that editing source code for an application or working in a development environment might somehow result in catastrophic and irreversible damage to the project. The result is oftentimes a paralysis of sorts, an unwillingness to touch source code or step into a development environment. The easiest solution to this is experience. As we describe, this experience can be thoughtfully engineered and fostered with an approach that scaffolds archaeologists and heritage professionals into greater levels of engagement and expertise with digital methods. More than this, however, it recognizes and respects the fact that many archaeologists and heritage professionals at all stages in their careers have differing levels of comfort with digital and computational methods, and it is the community's responsibility to accept and accommodate this.

\section{Understanding the Value of Failure}

Despite checks and balances (such as scrum, vision documents, and project milestones) projects often fall short of the original proposals. There have been a few instances (particularly in the case of the $\mathrm{CHI}$ Graduate Fellowship Program and the institute) in which projects failed entirely and didn't produce any tangible outcomes. In some cases, these failures resulted from unforeseen technical issues completely beyond the control of the developers. In some cases, they resulted from problems in acquiring necessary content or data. In other cases, it was just a matter of poor time management. Regardless of the reasons, we try to find value in any failure. This could mean identifying, discussing, and understanding the reason for the failure and exploring strategies to overcome the issue in the future. If the issue expresses itself early enough, we might downsize the project's scope or pivot the outcome or technical architecture so that the challenges might be avoided. The argument in this regard is twofold. First, any setting in which digital heritage and archaeology instruction is happening (curricular or extracurricular) must allow for and be understanding of failure. Second, failure must always have a positive outcome of some sort. Ultimately, it is a learning experience. Perhaps one of the strongest advocates for this approach comes from Graham (2018), who persuasively argues that sharing failure openly and constructively with a community of practice can have a powerful positive impact on success. In this way, we should think about failure within digital archaeology and heritage in a scientific way: experimentation, testing hypotheses, and releasing the results of that experimentation for the collective benefit.

\section{An Ethos of Openness}

Perhaps one of the strongest threads that runs thought much of what we do in these programs at MSU is a strong commitment to the idea and practice of openness. This expresses itself in a variety 
of ways. First, all the initiatives that we have discussed privilege the use of open-source tools and platforms. Open-source software supports sustainability, is more secure, is more financially accessible (as it is usually free to use), is more community driven, is not beholden to the whims of any corporate entity, is much more interoperable, and is built on de facto community standards. By extension, a commitment to using open-source software also means releasing work under an open-source license. By doing this, scholars and students contribute to the broader ecosystem of digital archaeology and heritage. In practical terms, this often means using GitHub to share code and develop openly. GitHub is hardly the only platform to do this, but it is the most popular and widely used. As such, using GitHub to build digital archaeology and heritage applications and digital experiences makes work more visible and accessible. By extension, a commitment to producing and consuming open-source software means a commitment to building on and for the open web.

Beyond open-source software, all three initiatives described build on the idea of working openly and writing publicly. Writing publicly about process and product creates connections between scholars and practitioners and is particularly valuable to students and new scholars. It encourages fruitful and valuable discussion and collaboration.

\section{Creating a Culture of Generosity}

Almost everything discussed in this article- building both capacity and community - is not possible if it does not exist within a culture of generosity. This is not something that happens by chance; it is something that must be engineered, fed, and fostered. Scholarship is sometimes seen as a zero-sum game in which ideas, work, and time need to be protected until the project is published, presented, or released. Digital archaeology and heritage can challenge these practices. A culture of generosity can be sewn into the fabric of any initiative intended to build digital capacity and community. Collaborative projects with shared goals and outcomes help accomplish this. Helping people understand the tangible professional benefits that come from being collaborative and generous with experience and expertise is rewarding. If there is one clear lesson to be learned from our work on digital heritage and archaeology at MSU, it is the importance of an environment in which people are social, teach each other, and are generous with their expertise, experience, code, data, tools, and time.

\section{Assessing Outcomes}

Outcomes for the three initiatives discussed herein, and the model itself, can be informally assessed against the goal to provide critical digital skills, perspectives, and experiences to students and scholars across the archaeological and heritage world so that they can more successfully address the digital challenges they face in their research or practice.

We have qualitative and anecdotal evidence that suggests participants in both the $\mathrm{CHI}$ Initiative and the Institute on Digital Archaeology Method \& Practice are gaining critical new perspectives with the potential to transform the way they work. In most cases, participants adopted and deployed digital methods in service of their primary scholarly focus. In several cases, participants in the Institute on Digital Archaeology Method \& Practice received major external funding (NEH, NSF, SSHRC) for projects with strong digital components. A small number of participants also took on digital methods and computational approaches as their core scholarly identity and specialty. Some participants in the initiatives already had experience with digital methods, but their work most often had been entirely self-directed and informal. For these participants, the initiatives provided a more systematic engagement with digital methods and computational approaches. Perhaps the most noticeable outcome in all cases was not so much the adoption of specific digital methods but the deeper and more thoughtful engagement with broader professional issues that have transformed through the increasing presence of digital methods and computational approaches in heritage and archaeology. Participants in all initiatives developed a more robust sense of the impact that digital and computational technologies have on publishing, preservation, data sharing, patrimony, copyright, public engagement, heritage management, and data access. We have seen a tangible, professional impact stemming from student participation in these initiatives. Over the nearly 10 years of the $\mathrm{CHI}$ Graduate Fellowship Program, nearly half the fellows who have graduated have gone on to positions that are either digitally focused or have a strong digital aspect to them, including positions on faculties, in labs, in research centers, at academic libraries, and in museums.

Beyond the desire to provide critical digital skills, perspectives, and experiences to students and scholars, these initiatives also seek to increase the number of thoughtfully developed digital archaeology and heritage applications and experiences, thereby increasing access to archaeological and heritage data, knowledge, and interpretation. This outcome is easy to assess given that the primary goal of all the initiatives discussed is the productions of a significant digital project. All projects for the $\mathrm{CHI}$ Graduate Fellowship Program and the Digital Cultural Heritage Fieldschool can be found at http://chi.anthropology.msu.edu/projects, and all projects from the Institute on Digital Archaeology Method \& Practice, at http://digitalarchaeology.msu.edu/news/. These projects exist on a spectrum; some are more robust and detailed than others. However, all are accessible, use real data and content, are designed for a real audience, and address a real need or issue.

Finally, as we have discussed at length, these initiatives seek to build communities of practice that share a specific perspective on the deployment of digital methods and computational

approaches in the service of heritage and archaeology. The connective tissue that exists between the participants in the Institute on Digital Archaeology Method \& Practice, especially, is astonishing. As mentioned, many participants have strong ties over social media, especially Twitter. In several cases, groups of previously unconnected participants have collaborated on digital projects or coauthored publications after leaving the institute. A recent example of this is the Open Digital Archaeology Textbook Environment (https://o-date.github.io/), an eCampusOntariofunded project to create an open digital textbook environment that introduces learners to the issues, methods, and techniques of digital archaeology. The project is directed by Shawn Graham (one of the institute faculty) and featured coauthored contributions from four institute participants.

While several of the initiatives discussed are ongoing, we argue that all three have helped to develop a sustainable model for thoughtful praxis in digital archaeology and heritage and have 
had a measurable impact on the work of many scholars and students. Our hope is that this model is replicable-as it offers a practical approach that can be adopted or adapted in a university, a community archaeology program, or a heritage institution-and that the model convincingly demonstrates the value of an approach to digital archaeology and heritage that is open, experimental, playful, collaborative, thoughtful, and generous.

\section{Acknowledgments}

The work presented herein on the Institute on Digital Archaeology Method \& Practice was made possible by an Institutes for Advanced Topics in the Digital Humanities grant (HT-50088-14) provided by the National Endowment for the Humanities Office of Digital Humanities. The staff of the National Endowment for the Humanities (and especially the Office of Digital Humanities) work tirelessly, selflessly, and often thanklessly on the behalf of scholars and institutions. Their efforts and support in the space of digital archaeology and heritage has become critical to the domain. In this regard, the author wishes to specifically extend a note of profound appreciation to Jennifer Serventi, senior program officer for the NEH Office of Digital Humanities, for her incredible support during the institute. The author gratefully acknowledges the vital collaboration with Dr. Lynne Goldstein, co-director of the Institute on Digital Archaeology Method \& Practice. Support for the Cultural Heritage Informatics Initiative at Michigan State University is provided by the Graduate School, the College of Arts \& Letters, the College of Social Sciences, the Department of History, the Department of Anthropology, and the Department of Writing, Rhetoric, and American Cultures. The author also gratefully acknowledges the unwavering support of Dr. Jodie O'Gorman (Chair, Department of Anthropology) for the Cultural Heritage Informatics Initiative. In addition, the author wishes to acknowledge the support that MATRIX: The Center for Digital Humanities and Social Sciences (especially Dr. Dean Rehberger, Director of MATRIX) and The Lab for the Education and Advancement in Digital Research (especially Mr. Brandon Locke, Director, and Dr. Alice Lynne McMichael, Assistant Director) have provided for all the projects and initiatives discussed in this article. The author also wishes to thank Dr. Alex Galarza (2011-2012 CHI grad fellow) for taking the time to translate this article's abstract into Spanish.

\section{Data Availability Statement}

No original data was used for this paper.

\section{References Cited}

Ascher, Marcia, and Robert Ascher

1963 Chronological Ordering by Computer. American Anthropologist 65(5):1045-52.

Cowgill, George L.

1967 Computer Applications in Archaeology. Computers and the Humanities 2(1):17-23.

1968 Archaeological Applications of Factor, Cluster, and Proximity Analysis. American Antiquity 33:367-75.

Chenhall, R G.

1967 The Description of Archaeological Data in Computer Language. American Antiquity 32:161-67.

1968 The Impact of Computers on Archaeological Theory: An Appraisal and Projection. Computers and the Humanities 3(1):15-24.

1971 The Archaeological Data Bank: a Progress Report. Computers and the Humanities 5(3):159-69.

Deetz, James

1965 The Dynamics of Stylistic Change in Arikara Ceramics. University of Illinois Press, Urbana.

Graham, Shawn

2018 Failing Productively. In The Open Digital Archaeology Textbook Environment, https://o-date.github.io/draft/book/failing-productively.html, accessed 29 December 2018

Lave, Jean, and Etienne Wenger

1991 Situated Learning: Legitimate Peripheral Participation. Cambridge University Press, Cambridge.

Scholtz, Sandra, and Robert Chenhall

1976 Archaeological Data Banks in Theory and Practice. American Antiquity 41:89-96

Watrall, Ethan

2016 Archaeology, the Digital Humanities, and the "Big Tent." In Debates in the Digital Humanities 2016, edited by Matthew K. Gold and Lauren F. Klein, pp. 345-358. University of Minnesota Press, Minneapolis.

Wenger, Etienne C., Richard McDermott, and Williams C. Snyder 2002 Cultivating Communities of Practice: A Guide to Managing Knowledge. Harvard Business School Press, Cambridge, Massachusetts.

Whallon, Robert, Jr.

1972 The Computer in Archaeology: a Critical Survey. Computers and the Humanities 7(1):29-45.

\section{AUTHOR INFORMATION}

Ethan Watrall $\square$ Department of Anthropology, Michigan State University, 655 Auditorium Drive, East Lansing, MI 48824 (watrall@msu.edu, corresponding author) 